\title{
Efficacy of Phlebiopsis gigantea against Heterobasidion conidiospore and basidiospore infection in spruce wood
}

\author{
Lauma Brūna ${ }^{(1)}$, \\ Dārta Klavinga ${ }^{(1)}$, \\ Astra Zaļuma ${ }^{(1)}$, \\ Kristīne Kenigsvalde (1), \\ Natālija Burṇeviča ${ }^{(1)}$, \\ Vizma Nikolajeva ${ }^{(2)}$, \\ Tālis Gaitnieks ${ }^{(1)}$, \\ Tuula Piri ${ }^{(3)}$
}

\begin{abstract}
Treatment of freshly cut stumps with biological control agents containing Phlebiopsis gigantea spores effectively restricts the spread of new Heterobasidion infections in conifer forests. To test the control efficacy of different $P$. gigantea strains, conifer stumps or billets cut from tree stems can be artificially infected with asexual Heterobasidion conidiospores or sexual basidiospores or left for natural basidiospore infection. Currently, no information is available about whether the control efficiency of $P$. gigantea in Norway spruce wood is affected by Heterobasidion spore type. In the present study, the impact of four $P$. gigantea strains (including the commercial product Rotstop ${ }^{\circledR}$ ) on initiation and development of Heterobasidion basidiospore and conidiospore infections as well as the relationship between the area occupied by $P$. gigantea and control efficacy were analysed in spruce billets. The mean size of the area occupied by $P$. gigantea was larger, and the efficacy of $P$. gigantea against Heterobasidion was significantly higher in billets left for natural basidiospore infection compared to treatment with Heterobasidion conidiospore suspension. The control efficacy against Heterobasidion infection was high, although only a small area of the billet surface was occupied by $P$. gigantea and even when there was no visible discoloration caused by $P$. gigantea infection on wood surfaces.
\end{abstract}

\section{Keywords: Picea abies, Billets, Conidiospores, Basidiospores}

chemical control agents (Holdenrieder \& Greig 1998, Pratt et al. 1998). Biological preparations containing asexual spores of Phlebiopsis gigantea - an antagonist of Heterobasidion species - are very effective in pine stumps but can be less effective in spruce stumps (Sun et al. 2009 and literature therein). However, good control efficiency can also be achieved in spruce wood when the spore concentration of treatment suspension is high, i.e., 5 million spores $\mathrm{L}^{-1}$ (Korhonen 2003). A commercial preparation of $P$. gigantea, Rotstop ${ }^{\circledast}$, was developed almost 30 years ago in Finland and is the most commonly used biological control agent against Heterobasidion root rot in Europe (Korhonen et al. 1994, Thor et al. 2006). However, the use of a genetically homogenous preparation may negatively affect fungal communities, therefore different studies were carried out to evaluate the impact of the biological control agent on below ground and stump colonizing fungal communities (Holdenrieder \& Greig 1998, Vainio et al. 2001, Roy et al. 2003, Vasiliauskas et al. 2004, Vasiliauskas et al. 2005, Menkis et al. 2012, Terhonen et al. 2013). Previous studies indicate that local $P$. gigantea strains can be as effective, or even better, than the Finnish strain used in Rotstop $^{\circledast}$ (Berglund et al. 2005). Therefore, studies have been carried out in several countries to identify local $P$. gigantea strains that could be used for controlling Heterobasidion root rot (Kenigsvalde et al. 2016 and literature therein).
Field testing of the efficiency of $P$. gigantea strains is usually done in stumps at sites with natural Heterobasidion spore infection (Korhonen et al. 1994, La Porta et al. 2003, Berglund \& Rönnberg 2004, Annesi et al. 2005, Berglund et al. 2005, Nicolotti \& Gonthier 2005, Rönnberg et al. 2006, Covert et al. 2013, Kenigsvalde et al. 2016). However, under in vivo conditions, the results can be influenced by several factors such as erratic densities of airborne Heterobasidion spores, as well as variable background levels of natural P. gigantea spore load (Berglund \& Rönnberg 2004, Gaitnieks et al. 2018). Laborious and long-lasting field experiments may even be inconclusive due to a lack of Heterobasidion infections in control stumps (Korhonen et al. 1994). The growth rate and efficiency of $P$. gigantea against Heterobasidion infection is also strongly dependent on the characteristics of individual trees (Sun et al. 2009). In several infection experiments, billets cut from tree stems have been used instead of stumps, or billets are used in conjunction with stumps (Holdenrieder 1984, Korhonen et al. 1994, Korhonen 2003, La Porta et al. 2003, Roy et al. 2003, Annesi et al. 2005, Sun et al. 2009). Cutting several billets from each tree reduces the variation due to differences between individual trees and enables the use of more controlled experimental conditions to efficiently acquire information about growth rate of $P$. gigantea strains and competitive ability against Heterobasidion. 
Although both artificial inoculation with conidial suspensions and natural or artificial basidiospore infection have been widely used in several studies testing the efficiency of $P$. gigantea preparations, only a few studies (and only using stumps of Pinus spp.) have been carried out to compare the efficiency of $P$. gigantea against both Heterobasidion basidio- and conidiospore infections under the same experimental conditions. Both in Pinus echinata and $P$. nigra ssp. laricio stumps, $P$. gigantea proved to be more efficient against infection caused by Heterobasidion conidiospores than by basidiospores (Kuhlman \& Hendrix 1964, Tubby et al. 2008). As the host tree species influences the control effect of $P$. gigantea as well as susceptibility to Heterobasidion species (Thomsen \& Jacobsen 2003, Garbelotto \& Gonthier 2013, Gonthier 2019, Zaluma et al. 2019), the results obtained in one tree species may not be applicable to others. Besides Scots pine stumps, Norway spruce stumps are the most important targets of stump treatment in northern and most of central Europe. Increased knowledge of interactions between P. gigantea and infection of Norway spruce by Heterobasidion with different spore types would assist in testing the efficiency of novel local P. gigantea strains.

The aim of the present study was: (i) to evaluate the efficacy of different Latvian P. gigantea strains to control Heterobasidion conidio- and basidiospore infections in spruce wood in maximally standardised Norway spruce wood (billets); and (ii) to analyse the relationship between occupied area and control efficacy of $P$. gigantea against infection caused by both types of Heterobasidion spores.

\section{Materials and methods}

\section{Preparation of billets}

This experiment was initiated in May 2010. Three trees of Norway spruce (Picea abies [L.] H. Karst; dbh: 13-21 cm) without visual signs of decay at stump level and with long branchless stems were felled in the experimental forests in Kalsnava, eastern Latvia ( $56^{\circ} 40^{\prime} 21^{\prime \prime} \mathrm{N}, 25^{\circ} 57^{\prime} 40^{\prime \prime} \mathrm{E}$ ). For transport from the forest to the experimental location, the stems were cut into one meter long logs. Immediately before treatment, the logs were cut into $20-30 \mathrm{~cm}$ long segments (billets). Billets were num- bered starting from the root collar. To avoid the effect of individual wood properties of each tree on the results, billets for each treatment variant were chosen randomly from all trees and also from different heights.

\section{Preparation of treatment suspensions}

Three Latvian $P$. gigantea strains and the biological control agent Rotstop ${ }^{\circledast}$ were used in the experiment. The Latvian strains of $P$. gigantea were selected based on the characteristics obtained in laboratory (Tab. 1) and field experiments (unpublished data except the data concerning the Latvian strain G1 - Kenigsvalde et al. 2016, Zaluma et al. 2019). For preparation of treatment suspension, each $P$. gigantea strain was cultured in six Petri dishes on malt extract agar medium for 3 weeks at $20{ }^{\circ} \mathrm{C}$ in dark conditions. Spore suspensions were prepared by washing the spores several times from one Petri dish with unsterilized tap water, agitating the colony gently three times with a glass triangle. Tap water was added to the spore suspension obtained to a final volume of one liter. To count the number of spores in the suspensions, 0.5 $\mathrm{mL}$ was transferred to a Petri dish containing malt extract agar medium and spread evenly.

$P$. gigantea spores were counted under a microscope (magnification 100x) within 30 sight fields distributed systematically over the dish. The total number of spores in suspension was calculated taking into account the number of spores in the sight field, the area of the sight field and the area of the Petri dish. Treatment suspensions were prepared 2-4 hours before the experiment and the spore concentration in suspension was adjusted to ca. 5000 spores $\mathrm{mL}^{-1}$. Suspension of Heterobasidion conidiospores was prepared as a mixture from two heterokaryotic H. annosum (ISm15, VMa15) and two H. parviporum (No.66 and S37-9.8) strains of Latvian origin. Suspensions were prepared by washing spores several times from one Petri dish of each Heterobasidion strain with tap water, agitating the colony gently three times with a glass triangle and creating a mixture of all four strains. Spore concentration in suspension was adjusted to ca. 500 spores $\mathrm{mL}^{-1}$.

\section{Treatments}

The upper surface of each billet was di-

Tab. 1 - Properties of the $P$. gigantea strains grown on malt extract agar medium at 20 ${ }^{\circ} \mathrm{C} .\left(^{*}\right)$ : Three repetitions per strain; $\left({ }^{* *}\right)$ : Two repetitions per strain.

\begin{tabular}{llcccc}
\hline Strain & Host tree species & $\begin{array}{c}\text { Growth } \\
\text { rate } \\
\left(\mathrm{mm} \mathrm{day}^{-1}\right)^{*}\end{array}$ & $\begin{array}{c}\text { Growth rate over } \\
\text { Heterobasidion colony } \\
\left(\mathrm{mm} \mathrm{day}^{-1}\right)^{* *}\end{array}$ & $\begin{array}{c}\text { Spore } \\
\text { production } \\
\text { (million/ }\end{array}$ \\
\hline J4 & Pinus sylvestris & 8.0 & 1.4 & 0.9 & 12.8 \\
\hline Kn107E & Picea abies & 6.5 & 0.8 & 0.7 & 18.5 \\
\hline G1 & P. abies/P. sylvestris & 7.1 & 1.4 & 0.9 & 47.3 \\
\hline Rotstop & P. abies & 7.8 & 0.9 & 0.8 & 42.9 \\
\hline
\end{tabular}

vided in two sectors leaving a two $\mathrm{cm}$ wide buffer zone between sectors to avoid cross contamination. Half of the billet upper surface was covered with a paper sheet while the other half was treated with a suspension of $P$. gigantea until the surface was wet, i.e., an approx. $1 \mathrm{~mm}$ thick layer. One hour after application of $P$. gigantea, the entire surface of 28 billets was inoculated with Heterobasidion conidiospore suspension. After treatment, these billets (treated with $P$. gigantea and Heterobasidion) were placed in the field $\left(56^{\circ} 40^{\prime} 51^{\prime \prime} \mathrm{N}, 25^{\circ} 57^{\prime} 53^{\prime \prime}\right.$ E). To avoid contact with soil, folding garden fabric was used and billets were watered regularly to provide appropriate moisture content for fungal growth.

The remaining 32 billets, treated with only $P$. gigantea strains, were transported to an experimental site $\left(56^{\circ} 41^{\prime} 39^{\prime \prime} \mathrm{N}, 25^{\circ} 54^{\prime} 14^{\prime \prime}\right.$ E) - a Norway spruce stand growing on drained peat soil; forest type: Oxalidosa turf. mel.; stand age: 65 years - and exposed to natural infection by Heterobasidion basidiospores. Billets were placed in a radius of 4 metres surrounding spruce logs and stumps with abundant Heterobasidion fruit body development. Development of fruit bodies was favoured by shaded location rich in vegetation. Exposure time in the experimental site was five days. The billets were then transported to the field and placed next to the other billets. In total, billets were incubated in the field for 4 weeks. Mean daily air temperature during incubation was $16^{\circ} \mathrm{C}$. In total, 60 billets (7 repetitions for each $P$. gigantea strain treated with Heterobasidion conidiospores and 8 repetitions for basidiospore infection of Heterobasidion) were analysed.

\section{Sampling and laboratory analysis}

After incubation in the field, one sample disc ( $3 \mathrm{~cm}$ thick) was cut from the top of the billets and a second disc $2-3 \mathrm{~cm}$ lower so that the underside of the second disc was $8 \mathrm{~cm}$ from the top of the billet. The discs were transported to the laboratory, debarked and washed with a stiff brush under running tap water. After that the discs were placed in loosely closed transparent plastic bags and incubated for 7 days at room temperature in the daylight. The lower side of the discs at depth of $3 \mathrm{~cm}$ and $8 \mathrm{~cm}$ from the top of the billet were examined. A plastic grid consisting of $0.49 \mathrm{~cm}^{2}$ squares was fixed on each disc with pins. A dissection microscope was used to examine each square for the presence of Heterobasidion conidiophores (area colonised by the fungus was marked on the disc with red dots). The area occupied by $P$. gigantea was identified by the typical orange brown colouration in wood. The surface area occupied by the fungus was redrawn on transparent paper and measured using a planimeter (PLANIX 10S "Marble", Tamaya, Japan).

\section{Calculations and statistics}

Efficacy of $P$. gigantea treatment was cal- 
culated taking into account the area occupied by Heterobasidion on sectors of the disc treated with $P$. gigantea (sapwood and heartwood included) and the area of Heterobasidion on the untreated (control) sector. The efficacy was calculated at depths of 3 and $8 \mathrm{~cm}$ from the billet surface, and results were obtained from 7 or 8 billet replicates. The following formula was used to calculate the efficacy of different $P$. gigantea strain treatments (eqn. 1):

$$
E(\%)=100-\left(100 \cdot \frac{n_{t}}{n_{u}}\right)
$$

where $n_{t}$ and $n_{u}$ represent the percentage of area occupied by Heterobasidion in treated and untreated sectors, respectively.

The correlation between the area occupied by $P$. gigantea and its control efficacy was calculated. Area occupied and efficacy between different $P$. gigantea strains were compared using the Mann-Whitney test in $R$ ( $R$ Core Team 2017). Percentages were arcsin transformed before calculations.

\section{Results}

Area occupied by P. gigantea

After Heterobasidion conidiospore infection, the mean area occupied by $P$. gigantea strains varied from $5.8 \%$ to $21.6 \%$ and from $0.6 \%$ to $5.1 \%$ at 3 and $8 \mathrm{~cm}$ depths, respectively (Tab. 2). All strains occupied a greater proportion of the disc area at a depth of $3 \mathrm{~cm}$ compared to $8 \mathrm{~cm}$ depth; moreover, the values differed significantly for strains J4, G1 and Rotstop ${ }^{\otimes}(p<0.05)$. Mean area occupied by strain $\mathrm{G} 1$ was significantly smaller in both analyzed depths compared to Rotstop ${ }^{\otimes}(p<0.05)$. Differences between strains were not significant at the $8 \mathrm{~cm}$ depth.

After Heterobasidion basidiospore infection, the mean area occupied by $P$. gigantea strains compared to total disc area varied from $23.6 \%$ to $31.4 \%$ and from $14.3 \%$ to $22.4 \%$ at 3 and $8 \mathrm{~cm}$ depths, respectively. No significant differences were found in the area occupied between $P$. gigantea strains at either analysed depth.

Mean area occupied by $P$. gigantea strains was significantly larger in billets infected by Heterobasidion basidiospores compared to conidiospores at a depth of $3 \mathrm{~cm}$ for the strain G1. Correspondingly, at a depth of 8 $\mathrm{cm}$ the $P$. gigantea strains $\mathrm{J} 4, \mathrm{G} 1$ and Kn107E occupied a significantly larger area after Heterobasidion basidiospore infection compared to conidiospore infection.

\section{Area occupied by Heterobasidion}

The area occupied by Heterobasidion mycelium after conidiospore inoculation was significantly smaller in sectors treated with $P$. gigantea compared to sectors without $P$. gigantea treatment. This applied to all analysed variants at both depths $(p<0.05)$, except for treatment with the $P$. gigantea strain $\mathrm{J} 4$ at a depth of $8 \mathrm{~cm}$ (Tab. 3). Mean

Tab. 2 - Mean area (\%, \pm standard error) occupied by P. gigantea after Heterobasidion treatment with conidiospores/basidiospores. (Strain): P. gigantea strain used for treatment.

\begin{tabular}{lcccc}
\hline \multirow{2}{*}{ Strain } & \multicolumn{2}{c}{ Conidiospore infection } & \multicolumn{2}{c}{ Basidiospore infection } \\
\cline { 2 - 5 } & Depth: $3 \mathrm{~cm}$ & Depth: $8 \mathrm{~cm}$ & Depth: $3 \mathrm{~cm}$ & Depth: $8 \mathrm{~cm}$ \\
\hline J4 & $10.5 \pm 4.1$ & $1.2 \pm 0.7$ & $23.6 \pm 6.6$ & $22.4 \pm 7.0$ \\
\hline G1 & $5.8 \pm 3.0$ & $0.6 \pm 0.4$ & $28.3 \pm 7.7$ & $20.9 \pm 7.7$ \\
\hline Kn107E & $10.1 \pm 5.5$ & $2.3 \pm 1.5$ & $25.6 \pm 6.9$ & $18.3 \pm 5.7$ \\
\hline Rotstop & $21.6 \pm 7.6$ & $5.1 \pm 1.6$ & $31.4 \pm 6.3$ & $14.3 \pm 4.5$ \\
\hline Mean & $12.0 \pm 3.4$ & $2.3 \pm 1.0$ & $27.2 \pm 1.7$ & $19.0 \pm 1.8$ \\
\hline
\end{tabular}

Tab. 3 - Mean area (\%, \pm standard error) occupied by Heterobasidion in sectors treated with $P$. gigantea and control sectors, analysed at depths of 3 and $8 \mathrm{~cm}$.

\begin{tabular}{|c|c|c|c|c|c|}
\hline \multirow{2}{*}{ Infection } & \multirow{2}{*}{ Strain } & \multicolumn{2}{|c|}{ Depth: $3 \mathrm{~cm}$} & \multicolumn{2}{|c|}{ Depth: $8 \mathrm{~cm}$} \\
\hline & & Treated & Control & Treated & Control \\
\hline \multirow{5}{*}{ 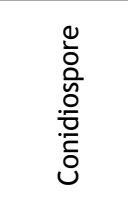 } & $J 4$ & $22.6 \pm 6.4$ & $46.6 \pm 8.5$ & $16.5 \pm 7.3$ & $19.9 \pm 6.9$ \\
\hline & G1 & $27.4 \pm 5.3$ & $59.7 \pm 5.1$ & $9.5 \pm 4.3$ & $25.3 \pm 4.6$ \\
\hline & Kn107E & $26.9 \pm 5.1$ & $54.7 \pm 4.0$ & $11.8 \pm 5.0$ & $31.9 \pm 3.0$ \\
\hline & Rotstop ${ }^{\oplus}$ & $5.6 \pm 2.1$ & $49.4 \pm 5.4$ & $12.0 \pm 3.1$ & $37.7 \pm 6.6$ \\
\hline & Mean & $20.6 \pm 5.1$ & $52.6 \pm 2.9$ & $12.5 \pm 1.5$ & $28.7 \pm 3.9$ \\
\hline \multirow{5}{*}{ 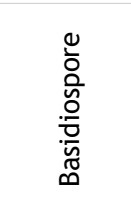 } & $\mathrm{J} 4$ & $3.0 \pm 1.0$ & $36.9 \pm 5.9$ & $1.8 \pm 0.7$ & $35.6 \pm 5.1$ \\
\hline & G1 & $2.9 \pm 0.8$ & $41.6 \pm 4.9$ & $2.7 \pm 1.1$ & $38.3 \pm 5.2$ \\
\hline & Kn107E & $4.2 \pm 2.1$ & $33.3 \pm 7.0$ & $2.9 \pm 1.8$ & $33.8 \pm 6.5$ \\
\hline & Rotstop ${ }^{\oplus}$ & $1.2 \pm 0.6$ & $33.4 \pm 6.8$ & $1.0 \pm 0.4$ & $30.6 \pm 7.2$ \\
\hline & Mean & $2.8 \pm 0.6$ & $36.3 \pm 2.0$ & $2.1 \pm 0.4$ & $34.6 \pm 1.6$ \\
\hline
\end{tabular}

area occupied by Heterobasidion in control sectors after conidiospore inoculation was significantly larger at a depth of $3 \mathrm{~cm}$ compared to $8 \mathrm{~cm}$ depth: $52.6 \%$ and $28.7 \%$, respectively.

The area occupied by Heterobasidion mycelium after natural basidiospore infection was significantly smaller in sectors treated with $P$. gigantea compared to sectors that were untreated in all analysed variants at both depths $(p<0.05)$. Variation of the areas occupied by Heterobasidion in control sectors was quite large. After conidiospore treatment, the area occupied by Heterobasidion ranged from $14.9 \%$ to $80.7 \%$ (average $52.6 \%$ ) and from $3.9 \%$ to $62.3 \%$ (average $28.7 \%$ ) at a depth of 3 and $8 \mathrm{~cm}$, respectively. After basidiospore infection, the area occupied by Heterobasidion varied from $2.9 \%$ to $70.3 \%$ (average $36.3 \%$ ) and from $9.7 \%$ to $70.9 \%$ (average $34.6 \%$ ) at a depth of 3 and $8 \mathrm{~cm}$, respectively.

Differences in the area occupied by Heterobasidion (in sectors treated with $P$. gi-

Tab. 4 - Mean efficacy of P. gigantea strains at a depth of 3 and $8 \mathrm{~cm}$ in Norway spruce billets.

\begin{tabular}{lccccc}
\hline \multirow{2}{*}{ Infection } & Depth & \multicolumn{4}{c}{ Strain Efficacy (\%) } \\
\cline { 3 - 6 } & & J4 & G1 & Kn107E & Rotstop $^{\circledR}$ \\
\hline \multirow{2}{*}{ Conidiospore } & $3 \mathrm{~cm}$ & 51.6 & 54.1 & 50.8 & 88.7 \\
& $8 \mathrm{~cm}$ & 47.1 & 62.5 & 63.1 & 68.3 \\
\multirow{2}{*}{ Basidiospore } & $3 \mathrm{~cm}$ & 91.8 & 93.0 & 87.2 & 96.4 \\
& $8 \mathrm{~cm}$ & 94.8 & 93.0 & 91.3 & 96.9 \\
\hline
\end{tabular}

gantea) at both analysed depths were significant between basidiospore and conidiospore infections. In addition, in the control sector (without $P$. gigantea treatment) at a depth of $3 \mathrm{~cm}$, the difference in area occupied by Heterobasidion was significant: $52.6 \%$ after conidiospore and $36.3 \%$ after basidiospore infection. In the control sector at a depth of $8 \mathrm{~cm}$, there were no significant differences between basidiospore and conidiospore infection in relation to the size of area colonized by Heterobasidion.

\section{Efficacy of $P$. gigantea against}

\section{Heterobasidion}

Mean efficacy of native $P$. gigantea strains and Rotstop ${ }^{\oplus}$ against conidiospore infection of Heterobasidion varied from $47 \%$ to $89 \%$ (Tab. 4). Efficacy of Latvian strains of $P$. gigantea was significantly lower compared to Rotstop ${ }^{\oplus}$ at a depth of $3 \mathrm{~cm}$ $(p<0.05)$. At a depth of $8 \mathrm{~cm}$, however, there were no statistical differences be- 
Conidiospore infection

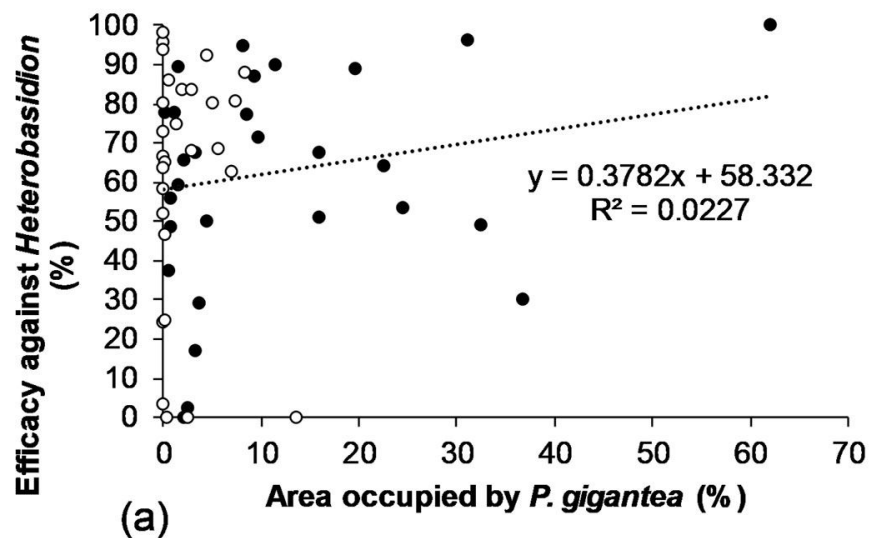

Basidiospore infection

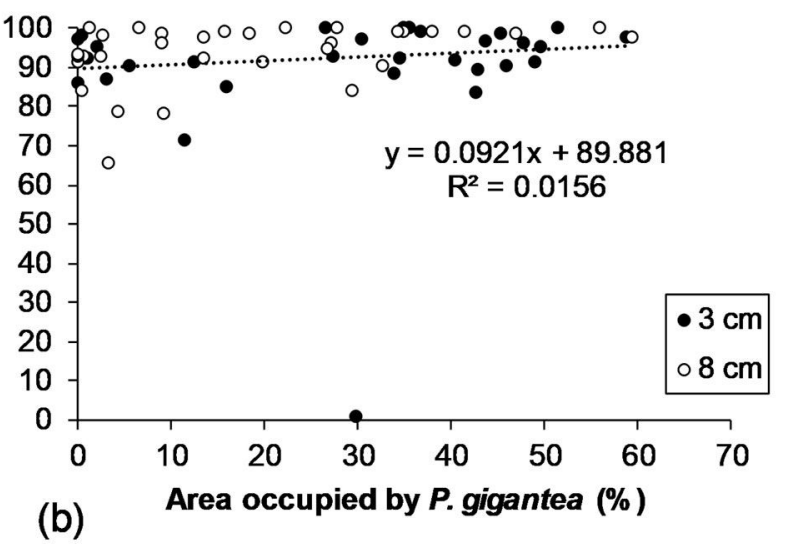

Fig. 1 - Relationship between area occupied by P. gigantea and efficacy against conidiospore (a) and basidiospore (b) infection of Heterobasidion in billets at a depth of 3 and $8 \mathrm{~cm}$.

tween $P$. gigantea strains ( $p>0.05)$. The efficacy at a depth of $8 \mathrm{~cm}$ was lower for $P$. gigantea strains $\mathrm{J}_{4}$ and Rotstop ${ }^{\oplus}$ but higher for $\mathrm{G} 1$ and Kn107E compared to a depth of $3 \mathrm{~cm}$.

Mean efficacy of $P$. gigantea strains against basidiospore infection of Heterobasidion varied from $87 \%$ to $96 \%$ and from $91 \%$ to $97 \%$ in a depth of 3 and $8 \mathrm{~cm}$, respectively. Rotstop ${ }^{\circledR}$ showed the highest efficacy at both analysed depths, but differences between the strains were not significant at either of the depths analysed. Mean efficacy of the three Latvian P. gigantea strains against conidiospore infection of Heterobasidion at a depth of 3 and $8 \mathrm{~cm}$ combined was $54.9 \%$ and for the Rotstop ${ }^{\circledR}$ strain $78.5 \%$. Mean efficacy of the Latvian $P$. gigantea strains against basidiospore infection of Heterobasidion (depths of 3 and $8 \mathrm{~cm}$ combined) was $91.9 \%$ compared to $96.7 \%$ for the Rotstop ${ }^{\oplus}$ strain.

Mean efficacy (combined data from both analysed depths) of $P$. gigantea was significantly higher in variants after Heterobasidion natural basidiospore infection instead to artificial conidiospore infection ( $p<0.05)$. Relationship between the area occupied by $P$. gigantea and efficacy against Heterobasidion (combined data of both analysed depths: 3 and $8 \mathrm{~cm}$ ) was not significant ( $p>0.05)$ in either conidiospore or in basidiospore infection (Fig. 1a, Fig. 1b).

\section{Discussion}

In this study, the efficacy of three Latvian $P$. gigantea strains and Rotstop ${ }^{\oplus}$ (commercial preparation of $P$. gigantea) against Heterobasidion infections caused naturally by basidiospores and artificially by conidiospores was evaluated in Norway spruce billets. In several studies analyzing the efficacy of chemical and biological control agents against Heterobasidion infection, conifer stumps and logs were treated with conidio- or basidiospores of the pathogen or left for airborne Heterobasidion inoculation (Nicolotti et al. 1999, Korhonen 2003,
Annesi et al. 2005, Nicolotti \& Gonthier 2005, Berglund et al. 2005, Rönnberg et al. 2006, Tubby et al. 2008, Lehtijärvi et al. 2011, Kenigsvalde et al. 2016, Oliva et al. 2017, Gonthier 2019). To our knowledge, our experiment is the first study where treatment efficacy of a $P$. gigantea isolate against Heterobasidion conidiospores (artificial infection) and basidiospore (natural) infection was characterized in a maximally standardized substrate such as spruce billets from the same trees. Four weeks after treatment, the area occupied by P. gigantea strains was larger in billets exposed to natural infection of Heterobasidion basidiospores than in billets artificially inoculated with Heterobasidion conidiospores. Because our experiment only lasted four weeks, it is possible that in the longer term the relationship regarding the areas occupied by $P$. gigantea and Heterobasidion may change.

As shown in earlier studies, number of both $P$. gigantea and Heterobasidion spores may be critical to the infection success and the following wood occupation (Korhonen et al. 1994, Berglund et al. 2005). In our study, Heterobasidion occupied a larger area on average after conidiospore infection in sectors treated with $P$. gigantea than after natural basidiospore infection. The advantages of artificial inoculation with Heterobasidion have been indicated in several studies (Thomsen 2003, Berglund \& Rönnberg 2004, Tubby et al. 2008). The advantage of artificial infection compared to natural spore infection was also demonstrated for $P$. gigantea in experiments with Pinus resinosa logs (Roy et al. 2003). In the previously mentioned study, two months after artificial infection with $P$. gigantea, the mycelium was found at a depth of $5 \mathrm{~cm}$ but at the depth of only one centimeter after natural infection. In our experiment, the billet surface was completely covered by $P$. gigantea suspension. Also the amount of spores in the treatment suspension was sufficiently high (ca. 5000 spores $\mathrm{mL}^{-1}$ ) to effectively prevent Heterobasidion infections in spruce wood (Korhonen 2003). For natural Heterobasidion basidiospore infection, the billets were placed close to fruit bodies to ensure sufficient spore load. The vast majority of the released basidiospores are deposited within a distance of a few meters from the fruit body (Kallio 1970, Stenlid 1994). The method used in our experiment ensured a high Heterobasidion infection rate (area occupied by Heterobasidion was on average $36.3 \%$ at a depth of 3 $\mathrm{cm}$ ) in analysed control sector of billets, whereas in similar studies in Sweden average Heterobasidion occupied area in control Picea abies stumps ranged from $0.70 \%$ to $2.12 \%$ (Berglund \& Rönnberg 2004, Rönnberg et al. 2006). Consequently, it is unlikely that a low density of basidiospores or conidiospores (i.e., 500 spores $\mathrm{mL}^{-1}$ ) had limited Heterobasidion infection in the present study. Thus, taking in account the area occupied by Heterobasidion in control sector, better efficiency of $P$. gigantea treatment against natural basidiospore than conidiospore infections may not be due to inadequate level of basidiospore inoculum. On the other hand, very high natural infection rate of Heterobasidion spores (Berglund \& Rönnberg 2004, Berglund et al. 2005, Kenigsvalde et al. 2016) as well as season of application (Gonthier 2019) can negatively affect the efficacy of biological control agents.

Norway spruce can be infected by both $H$. parviporum and $H$. annosum. However, H. parviporum is better adapted for spruce wood (Vasiliauskas \& Stenlid 1998, Oliva et al. 2013). As shown in Fig. 1, a greater variance of $P$. gigantea efficacy was unexpectedly observed after artificial treatment with Heterobasidion conidiospores, even though Heterobasidion basidiospore development may be more affected by other wood colonizing fungi in comparison to conidiospore development (Tubby et al. 2008, Oliva et al. 2013). Moreover, physical conditions, especially moisture, may have a 
greater impact on natural Heterobasidion basidiospore infection in the upper layers of stumps (Redfern 1982, 1993). In our experiment, conidiospore suspension contained both $H$. annosum and $H$. parviporum strains. The main reason for the high variance might probably be interspecies competition between different Heterobasidion genotypes (Redfern et al. 1997).

For the natural basidiospore infection the billets were exposed near $H$. parviporum fruit bodies (unpublished data). Therefore, the majority of basidiospores causing natural infection were probably derived from $\mathrm{H}$. parviporum. Inoculation experiments carried out by Gunulf et al. (2012) showed the competitive advantage of $H$. parviporum over $H$. annosum: $H$. parviporum totally replaced $H$. annosum in Norway spruce billets inoculated with a mixture of homokaryotic conidiospores of both species. Moreover, as also demonstrated in a study by Gunulf et al. (2012), H. parviporum grows successfully deeper in spruce wood compared to $H$. annosum. Dominance of $H$. parviporum may partly explain the result of our study indicating that infections caused by basidiospores were larger in area in the lower part of the control sector in billets.

In our experiment, we used billets cut from three individual trees instead of stumps in order to decrease variability due to differences between wood characteristics and of the individual trees. Despite maximizing the homogeneity of wood material, the variation in fungal colonization was high. The area occupied by Heterobasidion varied greatly both after conidiospore (4\%-81\%) and natural basidiospore (3\%-71\%) infections. A similar range in area occupied by Heterobasidion in Sitka spruce stumps after infection with Heterobasidion basidiospores (0.02\%-56.6\%), was found in a study by Morrison \& Redfern (1994). In our study with spruce billets, the area occupied by Rotstop ${ }^{\oplus}$ was on average $22.8 \%$. Whereas, a study in Sweden showed that area occupied by $P$. gigantea after treatment with Rotstop ${ }^{\circledast}$ in spruce stumps at depths of 2-12 $\mathrm{cm}$ was 5.9\% (Berglund \& Rönnberg 2004). Stumps can remain alive at least for 10 years after cutting if they have root contact with neighbouring trees (Redfern 1993). Unlike Heterobasidion, P. gigantea colonizes only deadwood, thus growth of $P$. gigantea is more likely to be inhibited in stumps than in billets (Vainio et al. 2001 and literature therein, Tubby et al. 2008). Thus, our results indicate that $P$. gigantea grows faster and may be more efficient against Heterobasidion infections in Norway spruce billets than in Norway spruce stumps.

In several studies $P$. gigantea efficacy is related to its occupied area (Korhonen 2003, Berglund \& Rönnberg 2004, Tubby et al. 2008). An earlier Latvian study indicated that when the area occupied by $P$. gigantea exceeds $10 \%$ of stump surface area, occurrence of Heterobasidion is significantly decreased (Kenigsvalde et al. 2016). Interest- ingly, in the present study, the efficacy of $P$. gigantea against conidiospore infection has been demonstrated even when $P$. gigantea occupied a relatively small area or when there was no discoloration in wood. Similar data was obtained in research carried out in Finland (Sun et al. 2011). It is possible that $P$. gigantea mycelium can be present in the wood and affect growth of Heterobasidion, but wood discoloration by $P$. gigantea appears only after longer period of incubation (K. Korhonen personal communication). This is supported by the results obtained by Oliva et al. (2017). By quantifying the biomass of H. annosum and $P$. gigantea in Norway spruce stumps, they reported that visual assessment after incubation may be a poor measure of presence or absence of both fungi. In Rotstop ${ }^{\oplus}$ treated stumps, no differences in biomass of $P$. gigantea could be found between areas with visual presence or absence of $P$. gigantea after incubation. For Heterobasidion, a significant difference in Heterobasidion biomass between areas with or without growth of Heterobasidion after incubation was found in stumps artificially inoculated with conidia suspension but not in naturally infected stumps (Oliva et al. 2017).

In several studies, the efficacy of the biological control agent Rotstop ${ }^{\circledast}$ varies from 50 to $100 \%$ (Korhonen 2003, Berglund \& Rönnberg 2004, Berglund et al. 2005, Nicolotti \& Gonthier 2005, Rönnberg et al. 2006, Cech et al. 2008, Kenigsvalde et al. 2016). In our study, the average efficacy of Rotstop ${ }^{\circledast}$ was $55 \%$ to $96 \%$. The average area occupied by the three Latvian P. gigantea strains after treatment with Heterobasidion conidiospores was smaller than after treatment with Rotstop ${ }^{\circledast}$. However, indigenous $P$. gigantea strains showed slightly higher occupation areas at a depth of $8 \mathrm{~cm}$ after Heterobasidion basidiospore infection. Efficacy of the local P. gigantea strain G1 used in our experiment has also been demonstrated in previous studies (Kenigsvalde et al. 2016). To limit the spread of Heterobasidion in the long term (via secondary infection) at a stand level, it is critical to restrict the growth of Heterobasidion mycelium deeper in the wood (Korhonen et al. 1994, Pettersson et al. 2003, Berglund \& Rönnberg 2004). Therefore, the obtained results demonstrate the potential of local P. gigantea strains to limit Heterobasidion infection in long term. Although in our experiment with Heterobasidion conidiospores local $P$. gigantea strains showed lower efficacy than Rotstop ${ }^{\circledR}$, with high ambient Heterobasidion natural basidiospore level, efficacy of the same $P$. gigantea strains was high.

\section{Conclusions}

Efficacy of $P$. gigantea treatment in a representative site was lower in Norway spruce billets after inoculation with conidiospores from four Heterobasidion strains belonging to two species than after natural infection through Heterobasidion basid- iospores. Therefore, spruce billets artificially inoculated with conidiospore suspension provide a reliable method for screening effective $P$. gigantea strains for controlling Heterobasidion spore infections on Norway spruce stumps. The commercial biological control agent Rotstop ${ }^{\circledast}$ was more effective against Heterobasidion conidiospore and natural basidiospore infection in spruce wood compared to the local $P$. gigantea strains used in the study. However, local $P$. gigantea strains have the potential to effectively limit advance of Heterobasidion infection deeper in the wood, thereby decreasing vegetative spread of Heterobasidion.

\section{Acknowledgements}

The authors thank Kari Korhonen for valuable comments, and Dainis Edgars Rungis for language revision. The authors gratefully thank to three anonymous referees for their suggestions to improve manuscript quality.

Study was financially supported by Joint stock company "Latvia's State Forests" project No. 5-5.5_0004_101_16_4 "Investigation of the factors limiting the spread of root rot", Latvian Council of Science fundamental and applied research project No. Izp-2018/1-0431 "Investigations on the role of Phlebiopsis gigantea in restricting vegetative spread of Heterobasidion spp. in stumps of Norway spruce and Scots pine", and in accordance with the contract No. 1.2.1.1/18/A/004 between Forest Sector Competence Centre of Latvia Ltd. and the Central Finance and Contracting Agency, the study "Development of biological preparation for reducing root rot caused losses in conifer stands" is conducted by LSFRI Silava with support from the ERDF within the framework of the project "Forest Sector Competence Centre of Latvia".

\section{References}

Annesi T, Gurcio G, Amico L, Motta E (2005). Biological control of Heterobasidion annosum on Pinus pinea by Phlebiopsis gigantea. Forest Pathology 35 (2): 127-134. - doi: 10.1111/j.1439-03 29.2004.00394.x

Berglund M, Rönnberg J (2004). Effectiveness of treatment of Norway spruce stumps with Phlebiopsis gigantea at different rates of coverage for the control of Heterobasidion. Forest Pathology 34 (4): 233-243. - doi: 10.1111/j.1439-0329.20 04.00363.x

Berglund M, Rönnberg J, Holmer L, Stenlid J (2005). Comparison of five strains of Phlebiopsis gigantea and two Trichoderma formulations for treatment against natural Heterobasidion spore infections on Norway spruce stumps. Scandinavian Journal of Forest Research 20 (1): 12-17. - doi: 10.1080/02827580510008202

Cech TL, Steyrer G, Lakomy P (2008). Preliminary results of Norway spruce stump treatment with Hypholoma fasciculare and Phlebiopsis gigantea in an Austrian Alpine protection forest. In: Proceedings of the " $12^{\text {th }}$ International Conference on Root and Butt Rots of Forest Trees" (Garbelotto M, Gonthier P eds). Berkeley (CA, USA) - Medford (OR, USA) 12-19 Aug 2007. The 
University of California, Berkeley, CA, USA, pp. 192-194.

Covert S, Brown J, Cram M (2013). A field trail testing Phlebiopsis gigantea as a biocontrol agent for Heterobasidion root disease in the southeastern United States. In: Proceedings of the IUFRO Working party 7.02.01 "Root and Butt Rots of Forest Trees" (Capretti P, Comparini C, Garbelotto M, La Porta N, Santini A eds). Firenze - San Martino di Castrozza (Italy) 4-10 Sept 2012. Firenze University Press, Firenze, Italy, pp. 183-184.

Gaitnieks T, Brauners I, Kenigsvalde K, Zaluma A, Bruna L, Jansons J, Burneviča N, Lazdinš A, Vasaitis R (2018). Infection of pre-commercially cut stumps of Picea abies and Pinus sylvestris by Heterobasidion spp. - a comparative study. Silva Fennica 52 (1): 1-7. - doi: 10.14214/sf.9911

Garbelotto M, Gonthier P (2013). Biology, epidemiology, and control of Heterobasidion species worldwide. Annual Review of Phytopathology 51 (1): 39-59. - doi: 10.1146/annurev-phyto082712-102225

Gonthier P (2019). Frequency of stump infections by Heterobasidion annosum s.l. and benefits from urea treatments vary with tree species and season in European Alpine forests. Forest Ecology and Management 343: 76-86. - doi: 10.1016/j.foreco.2018.12.011

Gunulf J, Rönnberg J, Berglund M (2012). Comparison of colonization capacity by asexual spores of Heterobasidion species in Norway spruce wood. Forest Pathology 42 (4): 338-344. - doi: 10.1111/j.1439-0329.2012.00763.x

Holdenrieder O (1984). Untersuchungen zur biologischen Bekämpfung von Heterobasidion annosum an Fichte (Picea abies) mit antagonistischen Pilzen. II. Interaktionstests auf Holz [Investigations on biological control of Heterobasidion annosum in Norway spruce with antagonistic fungi. II. Interaction experiments in wood]. European Journal of Forest Pathology 14 (3): 137-153. [in German] - doi: 10.1111/j.14390329.1984.tboog38.x

Holdenrieder O, Greig BJW (1998). Biological methods of control. In: "Heterobasidion annosum: Biology, Ecology, Impact, and Control" (Woodward S, Stenlid J, Karjalainen R, Hüttermann $A$ eds). $C A B$ International, Wallingford, UK, pp. 235-258.

Kallio T (1970). Aerial distribution of the root-rot fungus Fomes annosus (Fr.) Cooke in Finland. Acta Forestalia Fennica 107: 1-55. [online] URL: http://helda.helsinki.fi/bitstream/handle/1975/8 428/acta_1970_107_kallio.t.pdf

Kenigsvalde $\mathrm{K}$, Brauners I, Korhonen $\mathrm{K}$, Zaluma A, Mihailova A, Gaitnieks T (2016). Evaluation of the biological control agent Rotstop in controlling the infection of spruce and pine stumps by Heterobasidion in Latvia. Scandinavian Journal of Forest Research 31 (3): 254-261. - doi: 10.1080 /02827581.2015.1085081

Korhonen K (2003). Simulated stump treatment experiments for monitoring the efficacy of Phlebiopsis gigantea against Heterobasidion annosum. In: Proceedings of the IUFRO Working party 7.02.01 "Root and Butt Rots of Forest Trees" (Laflamme $G$, Bérubé JA, Bussières $G$ eds). Quebec (Canada) 16-22 Sept 2001. Natural Resources Canada, Canadian Forest Service, Ottawa, ON, Canada, pp. 206-210.
Korhonen K, Lipponen K, Bendz M, Johansson M, Ryen I, Venn K, Seiskari P, Niemi M (1994). Control of Heterobasidion annosum by stump treatment with "Rotstop", a new commercial formulation of Phlebiopsis gigantea. In: Proceedings of the IUFRO Working Party S2.06.01 "Root and Butt Rots" (Johansson M, Stenlid J eds). Wik (Sweden) - Haikko (Finland) 9-16 Aug 1993. Swedish University of Agricultural Sciences, Uppsala, Sweden, pp. 675-685.

Kuhlman EG, Hendrix FF (1964). Infection, growth rate, and competitive ability of Fomes annosus in inoculated Pinus echinata stumps. Phytopathology 54 (5): 556-561.

La Porta N, Grillo R, Ambrosi P, Korhonen K (2003). Stump treatment experiments against Heterobasidion in the Italian Alps. In: Proceedings of the IUFRO Working party 7.02.01 "Root and Butt Rots of Forest Trees" (Laflamme G, Bérubé JA, Bussières G eds). Quebec (Canada) 16-22 Sept 2001. Natural Resources Canada, Canadian Forest Service, Ottawa, ON, Canada, pp. 176-180. [online] URL: http://openpub.fma ch.it/handle/10449/16731\#.XzK7Zl9xe-4

Lehtijärvi A, Dogmus-Lehtijärvi HT, Aday AG, Oskay $F$ (2011). The efficacy of selected biological and chemical control agents against Heterobasidion abietinum on Abies cilicica. Forest Pathology 41 (6): 470-476. - doi: 10.1111/j.1439-0329.20 10.00705.x

Menkis A, Burokiene D, Gaitnieks T, Uotila A, Johannesson H, Rosling A, Finlay RD, Stenlid J, Vasaitis R (2012). Occurrence and impact of the root-rot biocontrol agent Phlebiopsis gigantea on soil fungal communities in Picea abies forests of northern Europe. FEMS Microbiology Ecology 81 (2): 438-445. - doi: 10.1111/fem.2012. 81.issue-2

Morrison DJ, Redfern DB (1994). Long-term development of Heterobasidion annosum in basidiospore-infected Sitka spruce stumps. Plant Pathology 43(5): 897-906. - doi: 10.1111/j.1365-30 59.1994.tbo1634.x

Nicolotti G, Gonthier P (2005). Stump treatment against Heterobasidion with Phlebiopsis gigantea and some chemicals in Picea abies stands in the western Alps. Forest Pathology 35 (5): 365374.

Nicolotti G, Gonthier P, Varese GC (1999). Effectiveness of some biocontrol and chemical treatments against Heterobasidion annosum on Norway spruce stumps. European Journal of Forest Pathology 29 (5): 339-346. - doi: 10.1046/j.14390329.1999.00159.x

Oliva J, Bernat M, Stenlid J (2013). Heartwood stump colonization by Heterobasidion parviporum and $H$. annosum s.s. in Norway spruce (Picea abies) stands. Forest Ecology and Management 295: 1-10. - doi: 10.1016/j.foreco.2013.01 .005

Oliva J, Messal M, Wendt L, Elfstrand M (2017). Quantitative interactions between the biocontrol fungus Phlebiopsis gigantea, the forest pathogen Heterobasidion annosum and the fungal community inhabiting Norway spruce stumps. Forest Ecology and Management 402: 253-264. - doi: 10.1016/j.foreco.2017.07.046

Pettersson M, Rönnberg J, Vollbrecht G, Gemmel P (2003). Effect of thinning and Phlebiopsis gigantea stump treatment on the growth of Heterobasidion parviporum inoculated in Picea abies. Scandinavian Journal of Forest Research 18 (4): 362-367. - doi: 10.1080/02827580310007 845

Pratt JE, Johansson M, Hüttermann A (1998). Chemical control of Heterobasidion annosum. In: "Heterobasidion annosum: Biology, Ecology, Impact, and Control" (Woodward S, Stenlid J, Karjalainen R, Hüttermann A eds). CAB International, Wallingford, UK, pp. 259-282.

R Core Team (2017). R: a language and environment for statistical computing. R Foundation for Statistical Computing, Vienna, Austria. [online] URL: http://www.r-project.org/

Redfern DB (1982). Infection of Picea sitchensis and Pinus contorta stumps by basidiospores of Heterobasidion annosum. European Journal of Forest Pathology 12 (1): 11-25. - doi: 10.1111/j.143 9-0329.1982.tb01367.x

Redfern DB (1993). The effect of wood moisture on infection of Sitka spruce stumps by basidiospores of Heterobasidion annosum. European Journal of Forest Pathology 23 (4): 218-235. doi: 10.1111/j.1439-0329.1993.tbo1340.x

Redfern DB, Gregory SC, Macaskill GA (1997). Inoculum concentration and the colonization of Picea sitchensis stumps by basidiospores of Heterobasidion annosum. Scandinavian Journal of Forest Research 12 (1): 41-49. - doi: 10.1080/028 27589709355382

Redfern DB, Stenlid J (1998). Spore dispersal and infection. In: "Heterobasidion annosum: Biology, Ecology, Impact, and Control” (Woodward S, Stenlid J, Karjalainen R, Hüttermann A eds). CAB International, Wallingford, UK, pp. 105-113. Rönnberg J, Sidorov E, Petrylaite E (2006). Efficacy of different concentrations of Rotstop and Rotstop ${ }^{\circledR}$ and imperfect coverage of Rotstop ${ }^{\circledast}$ against Heterobasidion s.l. spore infections on Norway spruce stumps. Forest Pathology 36 (6): 422-433. - doi: 10.1111/j.1439-0329.20 06.00476.x

Roy G, Laflamme G, Bussieres G, Dessureault M (2003). Field tests on biological control of Heterobasidion annosum by Phaeotheca dimorphospora in comparison with Phlebiopsis gigantea. Forest Pathology 33 (2): 127-140. - doi: 10.1046/j.1439-0329.2003.00319.x

Stenlid J (1994). Regional differentiation in Heterobasidion annosum. In: Proceedings of the IUFRO Working Party S2.06.01 "Root and Butt Rots" (Johansson M, Stenlid J eds). Wik (Sweden) - Haikko (Finland) 9-16 Aug 1993. Swedish University of Agricultural Sciences, Uppsala, Sweden, pp. 243-248.

Sun H, Korhonen K, Hantula J, Kasanen R (2009). Variation in properties of Phlebiopsis gigantea related to biocontrol against infection by Heterobasidion spp. in Norway spruce stumps. Forest Pathology 39 (2): 133-144. - doi: 10.1111/j.143 9-0329.2008.00574.x

Sun H, Paulin L, Alatalo E, Asiegbu FO (2011). Response of living tissues of Pinus sylvestris to the saprotrophic biocontrol fungus Phlebiopsis gigantea. Tree Physiology 31 (4): 438-461. - doi: 10.1093/treephys/tpro27

Terhonen E, Sun H, Buée M, Kasanen R, Paulin L, Asiegbu FO (2013). Effects of the use of biocontrol agent (Phlebiopsis gigantea) on fungal communities on the surface of Picea abies stumps. Forest Ecology and Management 310: 428-433. doi: 10.1016/j.foreco.2013.08.044 
Thomsen IM (2003). Effect of stump treatment on transfer of Heterobasidion annosum root rot in Norway spruce. In: Proceedings of the IUFRO Working party 7.02.01 "Root and Butt Rots of Forest Trees" (Laflamme G, Bérubé JA, Bussières G eds). Quebec (Canada) 16-22 Sept 2001. Natural Resources Canada, Canadian Forest Service, Ottawa, ON, Canada, pp. 160-169.

Thomsen IM, Jacobsen JB (2003). Testing of Rotstop on Sitka spruce, Douglas-fir and larch. In: Proceedings of the IUFRO Working party 7.02.01 "Root and Butt Rots of Forest Trees" (Laflamme G, Bérubé JA, Bussières $G$ eds). Quebec (Canada) 16-22 Sept 2001. Natural Resources Canada, Canadian Forest Service,, Ottawa, ON, Canada, pp. 217-218.

Thor M, Arlinger J, Stenlid J (2006). Heterobasidion annosum root rot in Picea abies: modelling economic outcomes of stump treatment in Scandinavian coniferous forests. Scandinavian Journal of Forest Research 21 (5): 414-423. - doi:
10.1080/02827580600917338

Tubby KV, Scott D, Webber JF (2008). Relationship between stump treatment coverage using the biological control product PG Suspension, and control of Heterobasidion annosum on Corsican pine, Pinus nigra ssp. laricio. Forest Pathology 38 (1): 37-46. - doi: 10.1111/j.1439-0329.200 7.00519.x

Vainio EJ, Lipponen K, Hantula J (2001). Persistence of a biocontrol strain of Phlebiopsis gigantea in conifer stumps and its effects on within-species genetic diversity. Forest Pathology 31 (5): 285-295. - doi: 10.1046/j.1439-0329.20 01.00249.x

Vasiliauskas R, Stenlid J (1998). Spread of S and $\mathrm{P}$ group isolates of Heterobasidion annosum within and among Picea abies trees in central Lithuania. Canadian Journal of Forest Research 28 (7): 961-966.

Vasiliauskas R, Lygis V, Thor M, Stenlid J (2004). Impact of biological (Rotstop) and chemical (urea) treatments on fungal community structure in freshly cut Picea abies stumps. Biological Control 31 (3): 405-413.

Vasiliauskas R, Larsson E, Larsson K-H, Stenlid J (2005). Persistence and long-term impact of Rotstop biological control agent on mycodiversity in Picea abies stumps. Biological Control 32 (2): 295-304. - doi: 10.1016/j.biocontrol.2004.10. 008

Witzell J, Berglund M, Rönnberg J (2011). Does temperature regime govern the establishment of Heterobasidion annosum in Scandinavia? International Journal of Biometeorology 55 (3): 275-284. - doi: 10.1007/s00484-010-0333-1

Zaluma A, Bruna L, Klavina D, Burnevica N, Kenigsvalde K, Lazdins A, Gaitnieks T (2019). Growth of Phlebiopsis gigantea in wood of seven conifer species. Forest Pathology 49(6): e12555. - doi: 10.1111/efp.12555 